\title{
Identifying the Role of Multidisciplinary Journals in Scientific Research
}

\section{Linda G. Ackerson and Karen Chapman}

\begin{abstract}
Scientists in focused research areas customarily use specialized journals, and yet multidisciplinary journals also are widely cited. Prior studies have investigated the characteristics of multidisciplinary journals, but none have considered the role this type of journal plays in scientific research. Citation data from Nature, Science, and Proceedings of the National Academy of Sciences were used to profile the articles in the journals and the articles that cite them. In particular, when citation occurred across disciplines, the reason for the citation was investigated.
\end{abstract}

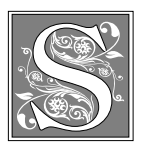

cientific communication is expressed in a wide array of formal methods, but especially as journal articles. Reports of scientific research and correspondence among scientists are published primarily in three types of journals. Some journals, such as Journal of the American Chemical Society, Mathematical Reviews, and Physical Review Letters, publish articles devoted to a single discipline. Others adopt a narrow focus and publish articles of primary interest to scientists working in specialized or interdisciplinary areas. Medical Engineering $\mathcal{E}$ Physics is an example of this type of journal. Finally, multidisciplinary journals, such as Nature and Science, publish articles from all scientific disciplines.

Only small, limited studies have focused on multidisciplinary journals, even though they are widely cited in the literature of many disciplines. This paper reports on a comprehensive study to determine the function this type of journal plays in supporting scientific research. The specific aim of the study was to determine whether multidisciplinary journals facilitate the transfer of information across disciplinary lines. Citation data from three journals were used to investigate these questions.

\section{Evolution of Multidisciplinary Journals}

Brian C. Vickery's excellent volume on the history of scientific communication traces the development of journal literature. ${ }^{1}$ Prior to the sixteenth century, individuals who kept records of observations were largely unaware of one another. Geography was a powerful barrier to sharing information. The formation of universities in densely populated urban areas and the succeeding development of organizations such as the Royal Society of London permitted scientists to attend informal meetings and exchange information. The minutes of these meetings were for-

Linda G. Ackerson is Assistant Engineering Librarian and Associate Professor of Library Administration at the University of Illinois at Urbana-Champaign; e-mail: lackerso@uiuc.edu. Karen Chapman is Business Reference Librarian, Angelo Bruno Business Library, at the University of Alabama; e-mail: kchapman@bruno.cba.ua.edu. 
mally documented, but the proceedings were slow to arrive to members of the society and not accessible to nonmembers. It was evident that a central source was needed to effectively disseminate information from formal meetings, informal discussions, and reports of experiments and discoveries. Philosophical Transactions of the Royal Society of London was the first English-language journal established to maintain communication among scientists in societies. The Transactions, first published in 1665, included reports from all areas of science.

During the 1700s, science flourished throughout Europe, accompanied by the proliferation of scientific societies. As the amount of knowledge increased, scientists began dividing themselves into more specialized areas and, as a result, the first specialized journals were established. With a smaller scope of coverage, scientists in the same specialty could share results more effectively without having to sift through all studies published at the same time. In addition, studies could be replicated more easily and discussed to stimulate continued work on research projects.

By the late 1800s, scientists found they were unable to keep up with the increasing number of new scientific developments, not only in their own disciplines, but in others as well. The pace at which full reports of original research were published and distributed was slowed due to the larger amount of literature being published in all subject areas. Multidisciplinary journals were first established as news magazines that could provide brief reports of completed research before the full reports were published elsewhere in peer-reviewed journals. By the 1960s, even news journals could not keep stride with new developments, so letters journals began to appear. Unlike multidisciplinary journals, letters journals were used to announce the results of research in one discipline, especially in newly developing interdisciplinary areas. Over time, letters journals were subdivided into very specialized newsletters, such as Arthropod-Borne Virus Information Exchange. Most recently, somejournals have begun publish- ing accounts of research online first for rapid dissemination, followed by publication in the print journal.

Despite the continuous subdivision of research-and therefore of journalsmultidisciplinary journals maintain a strong presence in scientific correspondence.

Impact factors for Nature, Science, and Proceedings of the National Academy of Sciences of the United States of America are among the highest in all disciplines. For this reason, these three journals were selected as the subjects of this study.

\section{Nature}

Nature began publication in the United Kingdom on November 4, 1869. The earliest issues were composed of news items but also included letters to the editor, editorials, book reviews, and a few reports of original research. Letters to the editor changed over the years. In the early issues, they were primarily comments on earlier articles. Around 1930, letters to the editor began to look like short research notes. By 1970, a well-developed table of contents had been added and what is traditionally considered as letters to the editor appeared in a section called "Correspondence," while short news items appeared in "News and Views." Currently, this weekly journal features results of original research; a variety of informal material, such as opinion pieces and news stories; contributed material, such as correspondence and commentary; literature reviews; and book, software, and product reviews.

Nature is part of a large family of international titles published by Macmillan Journals, Ltd. Seven titles in the familyNature Genetics, Nature Structural Biology, Nature Medicine, Nature Biotechnology, Nature Neuroscience, Nature Cell Biology, and Nature Immunology - publish original research in specialized areas. Three journals in this family-Nature Reviews Genetics, Nature Reviews Molecular Cell Biology, and Nature Reviews Neuroscience-provide monthly literature reviews. The general weekly journal Nature is the subject of this study. 


\section{Science}

The first issue of Science was published on February 9, 1883. The stated aim was that Science, published in the United States, would be equivalent to Nature but would focus on publishing immediate reports of scientific research performed by American scientists. Early issues included some full-length reports of original research; short research letters; news items; correspondence or letters to the editor; and book reviews. By 1885, brief research letters became more numerous and the journal assumed more structure, grouping types of articles.

Science suspended publication after volume 23, no. 581, in March 1894. When it resumed publication on January 4, 1895, the numbering started over with volume 1 , no. 1 . This new series covered mathematics, all physical sciences, engineering, life sciences, psychology, and anthropology. The editor's remarks about the new series stated that the purpose of the journal was to facilitate communication among all scientists in the United States on topics of broad interest, rather than in specialized areas. The American Association for the Advancement of Science has published Science since 1901 as a means of distributing the proceedings of meetings and scientific correspondence among the members of the association. By 1930, the contents of the journal also included summaries of scientific events, such as honorary and grant awards, along with reports on apparatus and methods. During the 1970s, life science articles began to appear more frequently in this journal.

\section{Proceedings of the National Academy of Sciences of the United States of America}

The first issue of the Proceedings of the $\mathrm{Na}$ tional Academy of Sciences of the United States of America (PNAS) was published on January 15,1915 , as the official organ of the National Academy of Sciences. It published reports of business and scientific meetings and included reports on awards and academy activities. It also was launched to serve as a vehicle for prompt publication of original research conducted by members of the academy. Because the journal attempts to serve all scientists represented in the academy, it favors the publication of papers that are of broad interest to scientists from many disciplines.

At the beginning, PNAS covered mathematics, all physical sciences, life sciences, psychology, and anthropology in a single volume. In 1965, engineering was added to the list of disciplines covered. Articles on biomedical topics became dominant by the 1970s. In 1980, PNAS broke into two parts, and the scope changed from publishing meeting proceedings to publishing reports of original theoretical and experimental research written by members of the academy. Part 1, "Physical Sciences," covered mathematics, astronomy, chemistry, physics, and statistics. Part 2, "Biological Sciences," covered biochemistry, biophysics, botany, cell biology, developmental biology, evolution, genetics, microbiology, neurobiology, physiology, population biology, and ecology. In 1985, PNAS reverted to a single publication and published fewer articles by being more selective in accepting manuscripts.

\section{Literature Review}

Earlier studies and informal observations of multidisciplinary journals have suggested that they serve one or more of the following functions:

- Stimulating new ideas: Carole L. Palmer's study of scientists at an interdisciplinary research center showed that scientists believe it is very important to remain aware of current research outside their own areas. ${ }^{2}$ Reading the primary literature in other areas was too time-consuming. Instead, they regularly scanned a number of general and multidisciplinary journals, such as Scientific American, $\mathrm{Na}$ ture, and Science, to find new ideas. A 1960 study of research chemists found that the most creative scientists read twice as much literature outside their own specialties than those who were less creative. ${ }^{3}$ By reading widely, scientists sometimes come across an interesting analogy or read an essay that suggests a different perspective on a problem. 
- Disseminating information to a broader audience: Multidisciplinary journals publish papers from a variety of disciplines, but the papers are not necessarily interdisciplinary. ${ }^{4}$ An article spanning more than one discipline may potentially double its readership. In addition, a combination of papers from the sciences, social sciences, and engineering in a single journal is likely to reach a more diverse audience of readers.

- Providing an outlet for unusual papers: Some studies involve research that does not fit into neat categories. For example, a newly emerging interdisciplinary area may not be developed enough to support a specialized journal. If the specific topic does not fit into any existing specialized journals, a multidisciplinary journal may be the only appropriate publication outlet.

- Providing cohesion within disciplines:S. Sarasvady and P. Pichappan hypothesized that the impact of a multidisciplinary journal such as Nature would be comparable to the impact of a specialized journal within the biomedical literature. ${ }^{5}$ They selected the sixty-three journals that the Institute for Scientific Information assigned to the subdiscipline of immunology, added Nature to the list, and ranked them according to impact factor. Nature was ranked twelfth on the list, affirming its place as a core journal in the subdiscipline of immunology.

\section{Selection of the Sample}

Multiple journals were selected for the study because the scope of journals may differ. Each may cover specific subject areas or favor one type of article over others. ${ }^{6}$ In separate studies, Braun and others and Kaneiwa and others compared Nature and Science. ${ }^{78}$ They found that Nature published papers from many countries in Europe, the United States, Australia, Canada, Japan, Switzerland, Sweden, The Netherlands, and Israel. Science, on the other hand, gave preferential treatment to the publications of scientists from U.S. institutions.

Articles from Nature, Science, and PNAS that were published in 1997 formed the basis for this study. The year 1997 was selected because it allowed enough time for the three-year citation peak to have occurred. The size of the population was assessed by the number of issues published in 1997. Nature and Science each published fifty-one issues, and PNAS published twenty-six issues. Within each issue, the number of articles was counted by the article type. A previous study of the citation impact of letters to the editor influenced the decision to include more than just original reports of completed research, demonstrating that different types of articles may serve different purposes. ${ }^{9}$ Four types of articles are published in multidisciplinary journals, so the number of each type of article in each issue was counted in order to generate a stratified sample, which would reflect the distribution of each type of article.

The first type of article is correspondence/opinion, which includes scientific correspondence among scientists, commentaries, essays, traditional letters to the editor, and public forums on scientific policy. The second type is completed research, which includes full-length articles of original research and brief research-quality notes that are published ahead of the full papers. The third type is reviews, which are variously titled as insights, reviews, progress reports, and perspectives. The fourth type of article is research in progress, composed primarily of brief summaries of ongoing research. Colloquium papers are included in this type, as the authors routinely submit their papers for comments prior to submitting them for peer review. Only signed articles were included in the count; named column editors were considered to be authors. Issue introductions, corrections, and obituaries were omitted, along with book and software reviews.

The counts for each type of article in each issue, summarized in table 1 , were submitted to the Illinois Statistics Office, a statistical consulting center operated by the Department of Statistics at the University of Illinois at Urbana-Champaign. The office used a sophisticated random number generator to create a stratified random sample of articles for each journal that reflected the numbers and types of articles that appeared in the journal. 
TABLE 1

Number of 1997 Articles, by Type

\begin{tabular}{lccccc}
\hline \hline Journal & $\begin{array}{c}\text { Correspondence/ } \\
\text { Opinion }\end{array}$ & $\begin{array}{c}\text { Completed } \\
\text { Research }\end{array}$ & Reviews & $\begin{array}{c}\text { Research in } \\
\text { Progress }\end{array}$ & Total \\
\hline Nature & 740 & 862 & 13 & 0 & 1,615 \\
PNAS & 71 & 2,515 & 18 & 67 & 2,671 \\
Science & 957 & 1,086 & 0 & 350 & 2,393 \\
\hline Total & $\mathbf{1 , 7 6 8}$ & $\mathbf{4 , 4 6 3}$ & $\mathbf{3 1}$ & $\mathbf{4 1 7}$ & $\mathbf{6 , 6 7 9}$ \\
\hline
\end{tabular}

The sample comprised sixty correspondence/opinion articles (twenty each from Science, Nature, and PNAS); sixty completed research articles (twenty each from Science, Nature, and PNAS); twenty-three review articles (five from Nature and eighteen from $P N A S$ ); and forty research-inprogress articles (twenty each from $\mathrm{Sci}$ ence and PNAS). Not all journals published the same types nor the same numbers of articles, which was reflected in the stratified sample; the total number of sample articles was 183.

Having identified a stratified random sample of articles that represented the articles published in 1997 in the selected multidisciplinary journals, the next step was to consider the articles that cited them. Each article in the sample was searched in Web of Science to identify the articles from the year 2000 that cited them. It was found that the 183 articles were cited a total of 7,551 times. Because this number of articles was too large to work with, a sample was created. Using the random number generator in the Excel software program, 10 percent of the citations of each cited article was randomly selected and 741 citing articles were identified.

\section{Data Collection}

The following data elements were gathered from each sample article: basic bibliographic details (title, author, and page numbers); the number of times the article was cited in 2000; and the subdiscipline and discipline of the article. The following data elements were recorded about each of the selected citing articles: basic bibliographic details (title, author, and page numbers), and the subdiscipline and discipline of the article. Each article was assigned a unique identification code to tie together the sample articles and citing articles so that they could easily be identified for further analysis.

The assignment of disciplinary labels is crucial to validate the cross-citation behavior among subject areas. One can safely assume that articles from the Journal of the American Chemical Society are about chemistry and articles from Tectonics concern earth sciences. The Institute for Scientific Information's Journal Citation Reports is an appropriate method of verifying this. However, multidisciplinary journals publish articles from all subject areas, so it is not possible to ascertain the true nature of an article only from the title of the journal. Using Journal Citation Reports in this instance would imply that all articles in multidisciplinary journals are multidisciplinary. Therefore, information about the articles in multidisciplinary journals must be collected at the article level, rather than at the journal level, in order to measure the characteristics of individual articles. ${ }^{10}$

A three-step method was employed to identify the disciplines of both sample and citing articles. Each article was searched in the Current Contents database. By using keywords assigned to the article and reading the abstract, the subdiscipline(s) of an article was determined. When an article could not be located in Current Contents, it was searched in Science Citation Index and the keywords and abstracts were used to determine the subdiscipline(s). In instances where information about a paper could not be located using one of these two indexes, the entire article was read and 
subdisciplinary labels were assigned based on subject content and author affiliation. When an article truly covered more than one subdiscipline, both were recorded rather than trying to fit the article into one subdiscipline or the other. Disciplinary labels were assigned based on the subdisciplines, as listed in table 2.

Life sciences literature was heavily represented in the three multidisciplinary journals. Using Francis Narin's example, the life sciences articles were separated into two separate disciplines. ${ }^{11}$ The areas that make up the biomedical sciences focus on human health, typified as research on the treatment of diseases, medical tech- niques, and medical specialties, and are of most interest to medical practitioners. Subdisciplines, such as botany, genetics, and zoology, were assigned to the biological sciences because they are of more interest to traditional biologists.

An additional aspect of this study was to determine the reason(s) why the sample articles were cited. The motive for citing an article can be determined by the section of the paper in which the citation occurs. An analysis of scientific and engineering papers from the past two hundred years shows that scientists and engineers organize the information they report in a topical structure and that the same type of

\begin{tabular}{|c|c|}
\hline & $\begin{array}{c}\text { TABLE } 2 \\
\text { Key to Disciplinary Assignment }\end{array}$ \\
\hline Discipline & Composed of Following Subdisciplines \\
\hline Astronomy & Astronomy \\
\hline Biological sciences & $\begin{array}{l}\text { Agriculture, anatomy, aquatic science, biology, biotechnology, } \\
\text { botany, cytology, developmental biology, ecology, environ- } \\
\text { ment, entomology, evolutionary biology, experimental biology, } \\
\text { genetics, microbiology, molecular biology, nutrition, physiol- } \\
\text { ogy, zoology }\end{array}$ \\
\hline Biomedical sciences & $\begin{array}{l}\text { Endocrinology, immunology, medicine, oncology, pathology, } \\
\text { pharmacology, toxicology, psychiatry, public health }\end{array}$ \\
\hline Chemistry & $\begin{array}{l}\text { Chemistry, materials chemistry, organic chemistry, physical } \\
\text { chemistry }\end{array}$ \\
\hline Earth sciences & $\begin{array}{l}\text { Atmospheric science, earth sciences, geology, oceanography, } \\
\text { petrology }\end{array}$ \\
\hline Education & Education \\
\hline Engineering & $\begin{array}{l}\text { Computer science, engineering, electrical engineering, } \\
\text { materials science, mechanical engineering }\end{array}$ \\
\hline Mathematics & Mathematics \\
\hline $\begin{array}{l}\text { Multidisciplinary } \\
\text { (sample combinations) }\end{array}$ & $\begin{array}{l}\text { Astronomy/physics, biology/chemistry, biology/geology, } \\
\text { biology/mathematics, biology/ physics, chemistry/computer } \\
\text { science, chemistry/engineering, chemistry/geology, chemistry/ } \\
\text { physics, earth sciences/political science, geology/physics, } \\
\text { materials science/physics, physics/engineering, sociology/ } \\
\text { anthropology }\end{array}$ \\
\hline Philosophy & Ethics \\
\hline Physics & Applied physics, optics, physics \\
\hline Political science & Political science, science policy \\
\hline Psychology & Psychology \\
\hline
\end{tabular}


TABLE 3

Composition of Sample and Citing Articles

\begin{tabular}{lrcrc}
\hline \hline \multirow{2}{*}{ Discipline } & \multicolumn{2}{c}{ Sample Articles } & \multicolumn{2}{c}{ Citing Articles } \\
& Number & Percentage & Number & Percentage \\
\hline Astronomy & 8 & $4 \%$ & 2 & $<1 \%$ \\
Biological sciences & 52 & $28 \%$ & 272 & $37 \%$ \\
Biomedical sciences & 29 & $16 \%$ & 209 & $28 \%$ \\
Chemistry & 2 & $1 \%$ & 17 & $2 \%$ \\
Earth sciences & 15 & $9 \%$ & 51 & $7 \%$ \\
Education & 4 & $2 \%$ & 1 & $<1 \%$ \\
Engineering & 5 & $3 \%$ & 10 & $1 \%$ \\
Mathematics & 8 & $4 \%$ & 4 & $<1 \%$ \\
Multidisciplinary & 34 & $19 \%$ & 132 & $18 \%$ \\
Philosophy & 6 & $3 \%$ & 1 & $<1 \%$ \\
Physics & 7 & $4 \%$ & 30 & $4 \%$ \\
Political science & 9 & $\mathbf{5 \%}$ & 2 & $<1 \%$ \\
Psychology & 4 & $\mathbf{2 \%}$ & 10 & $1 \%$ \\
\hline Total & $\mathbf{1 8 3}$ & $\mathbf{1 0 0 \%}$ & $\mathbf{7 4 1}$ & $\mathbf{1 0 0 \%}$ \\
\hline
\end{tabular}

information is almost always reported in the same section. ${ }^{12}$ The pattern of citation activity among disciplines (as opposed to within disciplines) was of special interest in assessing the purpose of multidisciplinary journals. In ninety-six cases, the subjects of a sample article and its citing article differed. These ninety-six articles were read to determine the section in which the sample article was cited.

Sample articles were cited in seven sections in the papers of other authors. The introduction provides justification for the research, formulation of the hypothesis, and the author's assumptions about the study. The information from a sample article cited in the introduction generally was used to support the author's line of reasoning. The literature review highlights prior relevant studies, thereby implying a common area of research across disciplines. The theory section discusses the principles and consequences of a particular premise and provides philosophical evidence to support it. The probable reason a sample article was cited in the theory section is because the citing author drew upon the theoretical principles of a different discipline. The experimental details specify materials, methods, and procedures used in performing the experiment.
When the sample article was cited in this section, it was most likely because techniques and computer programs used in the original study were adopted or modified by the citing author. The results section reports the outcomes of the experiment. Often sample articles cited in this section were used to support a point in an opinion article. In the discussion section, the citing author explains how the results of his or her study compare with the existing knowledge about a topic, including the study reported in the sample article. The conclusion summarizes the study and gives recommendations for future research. Usually, sample articles were cited in this section as examples of possible applications. Using this structure as a guide, the number of occurrences in each section was counted.

\section{Results and Discussion}

Table 3 shows the basic framework on which this study was based, giving the number and proportion of sample articles and citing articles in each discipline. Life sciences articles made up a significant proportion of coverage in multidisciplinary journals, especially in PNAS. This observation agrees with the study by Glanzel, Schubert, and Czerwon, who performed a subject analysis of Nature, Science, and 


\section{TABLE 4}

Nature: Number of Articles per Discipline, by Type

\begin{tabular}{lccccc} 
Discipline & $\begin{array}{c}\text { Correspondence/ } \\
\text { Opinion }\end{array}$ & $\begin{array}{c}\text { Completed } \\
\text { Research }\end{array}$ & Reviews & $\begin{array}{c}\text { Research in } \\
\text { Progress }\end{array}$ & Total \\
\hline Biological sciences & 5 & 4 & 3 & 0 & 12 \\
Biomedical sciences & 1 & 2 & 0 & 0 & 3 \\
Earth sciences & 3 & 3 & 1 & 0 & 7 \\
Multidisciplinary & 1 & 5 & 0 & 0 & 6 \\
Other sciences & 5 & 3 & 1 & 0 & 9 \\
Social sciences & 5 & 3 & 0 & 0 & 8 \\
\hline Total & $\mathbf{2 0}$ & $\mathbf{2 0}$ & $\mathbf{5}$ & $\mathbf{0}$ & $\mathbf{4 5}$ \\
\hline
\end{tabular}

PNAS. ${ }^{13}$ The life sciences articles published in these journals, especially those articles concerning biomedicine, drew the most citations. One sample biomedicine article had been cited 681 times within three years after publication.

The following three frequency tables give an in-depth look at the composition of the sample articles. Some disciplines were grouped in tables 4 through 6 when the number of articles in the discipline was too few to work with. The group labeled "Other sciences" includes astronomy, chemistry, engineering, mathematics, and physics. The group labeled "Social sciences" includes education, philosophy, political science, and psychology. Although philosophy is not traditionally considered a social science, the seven articles in this study that were classified as philosophy concerned ethical issues that are of interest to many social scientists and were included in this group.
Descriptive information about the individual journals also is shown in tables 4 through 6. For example, Nature does not publish research-in-progress articles but, instead, favors completed research and correspondence/opinion-type articles. PNAS publishes many reviews, whereas Science publishes none and Nature publishes only a few. Although all three journals published some social sciences articles, Science offered greater coverage, particularly in the form of correspondence/opinion-type articles.

Table 7 provides a broad look at crosscitation among the diverse disciplines represented in the sample articles. Crosscitation was based on frequency counts, so it was possible to tell if the sample articles were cited by the same discipline or by other disciplines, but it was not possible to assess citation among specific disciplines. There was great variation in cross-citation activity among journals. For

TABLE 5

PNAS: Number of Articles per Discipline, by Type

\begin{tabular}{lccccc} 
Discipline & $\begin{array}{c}\text { Correspondence/ } \\
\text { Opinion }\end{array}$ & $\begin{array}{c}\text { Completed } \\
\text { Research }\end{array}$ & Reviews & $\begin{array}{c}\text { Research in } \\
\text { Progress }\end{array}$ & Total \\
\hline Biological sciences & 8 & 8 & 7 & 6 & 29 \\
Biomedical sciences & 3 & 11 & 4 & 0 & 18 \\
Earth sciences & 0 & 0 & 0 & 7 & 7 \\
Multidisciplinary & 9 & 0 & 4 & 1 & 14 \\
Other sciences & 0 & 0 & 3 & 6 & 9 \\
Social sciences & 0 & 1 & 0 & 0 & 1 \\
\hline Total & $\mathbf{2 0}$ & $\mathbf{2 0}$ & $\mathbf{1 8}$ & $\mathbf{2 0}$ & $\mathbf{7 8}$ \\
\hline
\end{tabular}


TABLE 6

Science: Number of Articles per Discipline, by Type

\begin{tabular}{lccccc} 
Discipline & $\begin{array}{c}\text { Correspondence/ } \\
\text { Opinion }\end{array}$ & $\begin{array}{c}\text { Completed } \\
\text { Research }\end{array}$ & Reviews & $\begin{array}{c}\text { Research in } \\
\text { Progress }\end{array}$ & Total \\
\hline Biological sciences & 2 & 4 & 0 & 5 & 11 \\
Biomedical sciences & 2 & 5 & 0 & 1 & 8 \\
Earth sciences & 0 & 1 & 0 & 0 & 1 \\
Multidisciplinary & 3 & 7 & 0 & 4 & 14 \\
Other sciences & 0 & 3 & 0 & 9 & 12 \\
Social sciences & 13 & 0 & 0 & 1 & 14 \\
\hline Total & $\mathbf{2 0}$ & $\mathbf{2 0}$ & $\mathbf{0}$ & $\mathbf{2 0}$ & $\mathbf{6 0}$ \\
\hline
\end{tabular}

example, sample biomedical articles in Nature were used extensively by authors in other disciplines, whereas Science showed an opposite proportion. The same is true of citation of biological sciences in Science and PNAS. Earth sciences and social sciences literature exhibited the greatest extremes in citation in Science.

A. J. Meadows speculated that scientists who scanned multidisciplinary journals were unlikely to read the articles from other subject areas. ${ }^{14}$ He said they could go directly to specific subject areas of interest because the articles in these journals are grouped by subject. However, an examination of the subject arrangement in these journals did not find this to be true. Nature and Science group articles in each issue by type (e.g., research report or editorial), so subjects are published randomly throughout the issue. PNAS contains a table of contents that groups articles by type, but within each type, the articles are arranged by subject.

The assertion by Sarasvady and Pichappan that multidisciplinary journals could help scientists working in different subdisciplines to retain their disciplinary identity also was considered. ${ }^{15}$ By comparing the subdisciplines of sample articles with those of their citing articles, there was some evidence that this phenomenon does occur, mostly in the biomedical sciences. However, the instances of this phenomenon in other disciplines were too few to suggest that this was generally true.

Tables 8 and 9 provide an overview of the reasons why the sample articles were cited by articles from other disciplines. These data are derived from the ninetysix cases where the citing article's discipline differed from that of the sample article. Sample articles were cited more frequently in the introduction, literature re-

\begin{tabular}{|c|c|c|c|c|c|c|}
\hline \multicolumn{7}{|c|}{$\begin{array}{c}\text { TABLE } 7 \\
\text { Cross-citation Behavior of Citing Articles, by Discipline and Journal of } \\
\text { Cited Articles }\end{array}$} \\
\hline \multirow[t]{2}{*}{ Discipline } & \multicolumn{2}{|c|}{ Nature } & \multicolumn{2}{|c|}{ PNAS } & \multicolumn{2}{|c|}{ Science } \\
\hline & $\begin{array}{c}\text { Same } \\
\text { Discipline }\end{array}$ & $\begin{array}{l}\text { Different } \\
\text { Discipline }\end{array}$ & $\begin{array}{c}\text { Same } \\
\text { Discipline }\end{array}$ & $\begin{array}{c}\text { Different } \\
\text { Discipline }\end{array}$ & $\begin{array}{c}\text { Same } \\
\text { Discipline }\end{array}$ & $\begin{array}{r}\text { Different } \\
\text { Discipline }\end{array}$ \\
\hline Biological sciences & $59 \%$ & $41 \%$ & $69 \%$ & $31 \%$ & $30 \%$ & $70 \%$ \\
\hline Biomedical sciences & $21 \%$ & $79 \%$ & $55 \%$ & $45 \%$ & $70 \%$ & $30 \%$ \\
\hline Earth sciences & $86 \%$ & $14 \%$ & $30 \%$ & $70 \%$ & $100 \%$ & $0 \%$ \\
\hline Multidisciplinary & $22 \%$ & $78 \%$ & $45 \%$ & $55 \%$ & $36 \%$ & $64 \%$ \\
\hline Other sciences & $49 \%$ & $51 \%$ & $44 \%$ & $56 \%$ & $59 \%$ & $41 \%$ \\
\hline Social sciences & $26 \%$ & $74 \%$ & $25 \%$ & $75 \%$ & $0 \%$ & $100 \%$ \\
\hline
\end{tabular}




\begin{tabular}{|c|c|c|c|}
\hline \multicolumn{4}{|c|}{$\begin{array}{c}\text { TABLE } 8 \\
\text { Among Sample Articles Cited in a Different } \\
\text { Discipline, Number Cited per Section, by } \\
\text { Source of Sample Article }\end{array}$} \\
\hline Section Cited & Nature & PNAS & Science \\
\hline Introduction & 23 & 9 & 7 \\
\hline Literature review & 15 & 3 & 3 \\
\hline Discussion & 15 & 5 & 2 \\
\hline Experimental details & 1 & 4 & 1 \\
\hline Conclusion & 5 & 2 & 1 \\
\hline Results & 3 & 1 & 0 \\
\hline Theory & 4 & 0 & 0 \\
\hline
\end{tabular}

tensive literature surveys of current knowledge on a topic) also received about 25 percent of the total. This type of information is most likely to be found in the literature review of a citing paper. The results of the present study agree only partly with those of Mendez and Gomez. Although the sample articles were most likely to be cited in the introduction and literature review sections of citing papers, inferring a transfer of ideas across disciplines, there was

view, and discussion sections of other articles and less frequently in the results and theory sections. This was true in the most common pairings (e.g., chemistry article citing a physics article) and the least common pairings (e.g., mathematics article citing a biological sciences article).

Aida Mendez and Isabel Gomez's 1989 study of citation classics offers some comparative data. ${ }^{16}$ Their study revealed that basic research articles (articles that describe a new theory or model, or present new experimental data) received about 50 percent of the total citations. This type of information is most likely to be found in the introduction section of a citing paper. Methodological articles (articles that describe methods or techniques) received about 25 percent of the total citations. This type of information is most likely to be cited in the experimental details section. Reviews (ex- little evidence that methods and materials were shared among disciplines.

\section{Conclusions}

The objective of this study was to determine the role of multidisciplinary journals in scientific research and especially to assess the extent to which multidisciplinary journals support the transfer of information across disciplinary lines. The characteristics of intradisciplinary citation were not measured in this study and may be different from citation among disciplines. The three journals chosen for study proved to be diverse, in both the scientific disciplines they include and the types of articles they publish. All three publish articles characterized as multidisciplinary, but most of the articles concern one discipline.

The citation characteristics also revealed varying results among the disciplines cov-

\section{TABLE 9}

Among Sample Articles Cited in a Different Discipline, Number Cited by Section, by Type of Sample Article

\begin{tabular}{lcccc}
\hline Section Cited & $\begin{array}{c}\text { Correspondence/ } \\
\text { Opinion }\end{array}$ & $\begin{array}{c}\text { Completed } \\
\text { Research }\end{array}$ & Reviews & $\begin{array}{c}\text { Research in } \\
\text { Progress }\end{array}$ \\
\hline Introduction & 2 & 19 & 10 & 8 \\
Literature review & 1 & 15 & 2 & 3 \\
Discussion & 2 & 14 & 5 & 1 \\
Experimental details & 0 & 3 & 1 & 2 \\
Conclusion & 1 & 2 & 3 & 2 \\
Results & 2 & 1 & 1 & 0 \\
Theory & 1 & 2 & 1 & 0 \\
\hline
\end{tabular}


ered by the three journals. In some cases, articles from one discipline were cited almost exclusively by the same or a closely related discipline. The majority of cross-disciplinary sharing of information occurred in the life sciences, between biologists and biomedical researchers. In other cases, articles from one discipline were cited almost exclusively by other disciplines. None of the social science articles in the sample were cited by other social scientists. For example, a sample article on political science was cited by a biologist to illustrate a potential problem between social needs and the genetic engineering of crops.

This study also investigated why articles from one discipline are used by other disciplines. Sample articles were referenced most often in the introduction and literature review sections of citing articles to support the author's line of reasoning or to highlight common research areas. This study supports the notion that articles in multidisciplinary journals are exposed to a broad audience, thus facilitating the transfer of ideas across disciplines. However, there is little evidence to demonstrate the transfer of methodology across disciplines.

Variation among multidisciplinary journals is an important consideration for future research in this area because the results of this study demonstrate that the characteristics of all multidisciplinary journals cannot be generalized from the study of only one. In addition, the results of this study suggest that multidisciplinary journals play more than one role in scientific research. Further studies that focus on intradisciplinary citation in multidisciplinary journals are needed. Studies that gather comparative data from single-discipline journals, especially looking at the sections in which same-discipline articles are cited, also will further refine our understanding of the function of multidisciplinary journals.

\section{Notes}

1. Brian C. Vickery, Scientific Communications in History (Lanham, Md.: Scarecrow Pr., 2000).

2. Carole L. Palmer, "Information Work at the Boundaries of Science," Library Trends 45, no. 2 (fall 1996): 165-69.

3. A. J. Meadows, "Literature Usage and the Passage of Time," in Communication in Science (London: Butterworths, 1974), 126-51.

4. Diana M. Hicks and J. Sylvan Katz, "Where Is Science Going?" Science, Technology \& Human Values 21, no. 4 (fall 1996): 379-406.

5. S. Sarasvady and P. Pichappan, "Classification of Multidisciplinary Journals: The Study of the Journal 'Nature'," in Proceedings of the $8^{\text {th }}$ International Conference on Scientometrics and Infometrics, Sydney, Australia (Dordrecht, Netherlands: Klawer, 2001), 639-46.

6. Meadows, "Literature Usage and the Passage of Time."

7. T. Braun, W. Glanzel, and A. Schubert, "National Publication Patterns and Citation Impact in the Multidisciplinary Journals 'Nature' and 'Science',"' Scientometrics 17, no. 1-2 (1989): 11-14.

8. K. Kaneiwa et al., "A Comparison between the Journals 'Nature' and 'Science'," Scientometrics 13, no. 3-4 (1988): 125-33.

9. Bluma C. Peritz, "The Citation Impact of Letters to the Editor: The Case of 'Lancet'," Scientometrics 20, no. 1 (1991): 121-29.

10. W. Glanzel, A. Schubert, and H.-J. Czerwon, "An Item-by-Item Subject Classification of Papers Published in Multidisciplinary and General Journals Using Reference Analysis," Scientometrics 44, no. 3 (1999): 427-39.

11. Francis Narin, Evaluative Bibliometrics: The Use of Publication and Citation Analysis in the Evaluation of Scientific Activity (Springfield, Va.: National Technical Information Service, PB 252 339, 1976), 195-96.

12. Joseph E. Harmon, "A Structure of Scientific and Engineering Papers," IEEE Transactions on Professional Communications 32, no. 3 (Sept. 1989): 132-38.

13. Glanzel, Schubert, and Czerwon, "An Item-by-Item Subject Classification of Papers Published in Multidisciplinary and General Journals Using Reference Analysis."

14. A.J. Meadows, "Diffusion of Information across the Sciences," Interdisciplinary Science Reviews 1, no. 3 (1976): 259-67.

15. Sarasvady and Pichappan, "Classification of Multidisciplinary Journals," 427-39.

16. Aida Mendez and Isabel Gomez, "A Comparison of Citation Classics in Three Fields of Science," Scientometrics 15, no. 5-6 (1989): 621-31. 